\title{
Robotic-assisted Ivor Lewis esophagectomy: technique and early outcomes
}

This article was published in the following Dove Press journal:

Robotic Surgery: Research and Reviews

27 September 2017

Number of times this article has been viewed

\author{
Ian Nora' \\ Ravi Shridhar ${ }^{2}$ \\ Kenneth Meredith ${ }^{3}$ \\ 'Graduate Entry Medical School, \\ University of Limerick, Limerick, \\ Ireland; ${ }^{2}$ Central Florida University, \\ Orlando, ${ }^{3}$ Florida State University, FL, \\ USA
}

\begin{abstract}
Esophagectomy is pivotal for the long-term survival in patients with early stage and advanced esophageal cancer, and improved perioperative care and advanced surgical techniques have contributed to reduced postoperative morbidity. However, despite these advances, esophagectomy continues to be associated with significant morbidity and mortality. Minimally invasive esophageal surgery (MIE) has been increasingly used in patients undergoing surgery for esophageal cancer. Potential advantages of MIE include the decreased postoperative pain; lower postoperative wound infection, decreased pulmonary complications, and decreased length of hospitalization. Robotic esophageal surgery has the ability to overcome some of the limitations of laparoscopic and thoracoscopic approaches to esophagectomy while maintaining the benefits of the minimally invasive approach. In this article, we will review the clinical efficacy and outcomes associated with robotic-assisted Ivor Lewis esophagectomy (RAIL).

Keywords: robotic-assisted Ivor Lewis esophagectomy, esophageal cancer, minimally invasive esophagectomy
\end{abstract}

\section{Introduction}

It is estimated that there will be 16,910 new cases of esophageal cancer diagnosed, with 15,690 dying from the disease in the USA in $2016 .{ }^{1}$ The majority of esophageal cancers are either adenocarcinoma or squamous cell carcinoma. Although surgical resection is the accepted treatment for early-stage disease, the use of trimodality therapy of neoadjuvant chemoradiation (NCR) followed by surgical resection has been associated with improved survival for advanced disease. ${ }^{2,3}$

Esophagectomy is pivotal for the long-term survival in patients with early stage and advanced esophageal cancer, and improved perioperative care and advanced surgical techniques have contributed to reduced postoperative morbidity. However, despite these advances, esophagectomy continues to be associated with significant morbidity and mortality.,5 Although survival for patients with resected esophageal cancer has improved with the institution of multimodality treatment, the morbidity from esophagectomy remains high at $30 \%-60 \%{ }^{6-13}$ Traditionally, esophagectomy is performed through two to three large incisions via transabdominal or transthoracic approach. ${ }^{14-19}$ Ivor Lewis esophagectomy (ILE) is a common surgical approach for esophageal resection. The other approaches that are routinely used are the transhiatal esophagectomy (THE) and three-field esophagectomy. ILE is performed using both a right posterolateral thoracotomy incision and an abdominal incision.

A significant source of the morbidity from this approach is due to the right thoracotomy. These complications include significant postoperative pain, atelectasis,
Correspondence: Kenneth Meredith I540 Arlington Suite 10 I, Sarasota, FL, 34239, USA

Tel +l 94I 5045672

Email Kenneth-meredith@smh.com 
pneumonia, and atrial fibrillation with pulmonary and wound complications being the most common morbidities associated with the transthoracic approach. Minimally invasive esophageal surgery (MIE) has been increasingly used in patients undergoing surgery for esophageal cancer. Potential advantages of MIE include the decreased postoperative pain; lower postoperative wound infection, decreased pulmonary complications, and decreased length of hospitalization (LOH). Robotic esophageal surgery has the ability to overcome some of the limitations of laparoscopic and thoracoscopic approaches to esophagectomy. Specifically, it allows for a broader view of the operative field in the mediastinum, three-dimensional camera views, as well as greater range of instrument motion and articulation. The application of laparoscopic, thoracoscopic, and robotic approaches to esophageal resection have demonstrated equivalent oncologic outcomes compared to open techniques ${ }^{20-23}$ with some authors reporting benefit in postoperative morbidity. ${ }^{24,25}$

\section{Methods}

A query was performed utilizing PubMed with keywords "robotic esophagectomy, Ivor Lewis esophagectomy, and trans-thoracic esophagectomy" to identify existing peerreviewed manuscripts reporting outcomes associated with robotic esophagectomy. One hundred twenty-five manuscripts were identified and 51 were included in this review.

We then performed a retrospective review of the author's prospective robotic esophageal database of patients undergoing robotic-assisted Ivor Lewis esophagectomy (RAIL) from 2009 to 2014 after obtaining study approval from our Institutional Review Board (IRB\#15-onc-23). All patients, regardless of age, race, tumor stage or location, or neoadjuvant therapy, were included in the cohort. Patients were required to have a tissue diagnosis of high-grade dysplasia or cancer, but were not excluded based upon histologic variant. Basic demographics, tumor characteristics, operative details, and postoperative outcomes were recorded. Patients were included only if they underwent RAIL. Patients with midesophageal tumors who underwent McKeown or transhiatal esophagectomy were excluded from this analysis. All patients underwent intra-corporeal intra-thoracic anastomosis with robotic assistance.

\section{End points and statistical analysis}

The primary end points were operating room (OR) time, estimated blood loss (EBL), intensive care unit days following surgery, and LOH. Secondary end points included perioperative adverse events (AE) (<90 days following surgery), including pneumonia, cardiac arrhythmia, deep vein thrombosis (DVT)/pulmonary embolism (PE), wound infection, leak, and 90-day mortality. Readmissions and outcomes with neoadjuvant therapy were also analyzed.

Statistical analysis was performed using SPSS version 21.0 (IBM Corp, Armonk, NY, USA). Continuous variables were compared using the Kruskal-Wallis or the analysis of variance tests as appropriate. Pearson's chi-square test was used to compare categorical variables. All statistical tests were two-sided and an $\alpha$ (type I) error $<0.05$ was considered statistically significant.

\section{Open versus MIE}

Biere et al conducted the first randomized trial of open esophagectomy versus MIE. ${ }^{26}$ In that trial, 56 patients were randomized to the open esophagectomy group and 59 to the MIE group. Open esophagectomy was associated with higher pulmonary infection; 29\% versus 9\%; (relative risk, 0.30 ; $95 \%$ confidence interval, $0.12-0.76 ; p=0.005)$. LOH stay was lower in MIE patients ( 11 versus 14 days; $p=0.044$ ). For in-hospital mortality, one patient in the open esophagectomy group died from anastomotic leakage and two in the minimally invasive group from aspiration and mediastinitis after anastomotic leakage.

A second randomized trial of open versus MIE of 221 patients also confirmed decreased LOH stay and fewer pulmonary infections. ${ }^{27}$ The Society of Thoracic Surgeons National Database was queried to determine the outcomes of open versus MIE patients. ${ }^{28}$ The analysis compared both open ILE (1291) and THE (214) against MIE ILE (600) and THE (214) patients. Morbidity and all-cause mortality were equivalent between open and MIE. MIE was associated with longer median procedure times (443.0 versus 312.0 minutes; $p<0.001)$, but a shorter median LOH stay $(9.0$ versus 10.0 days; $p<0.001)$. Patients who underwent MIE had higher rates of reoperation $(9.9 \%$ versus $4.4 \% ; p<0.001)$ and empyema ( $4.1 \%$ versus $1.8 \% ; p<0.001)$. Open technique led to an increased rate of wound infections $(6.3 \%$ versus $2.3 \% ; p<0.001)$, postoperative transfusion $(18.7 \%$ versus $14.1 \% ; p=0.002)$, and ileus ( $4.5 \%$ versus $2.2 \% ; p=0.002)$. Propensity score-matched analysis confirmed these findings. High- and low-volume centers had similar outcomes. Similar findings were confirmed in an analysis of the National Cancer Database. ${ }^{29}$ Among 4,266 patients included, 1,308 (30.6\%) underwent MIE. MIE was more likely to be performed at academic centers or comprehensive cancer facilities. MIE patients had more lymph nodes retrieved (15 versus 13; $p=0.016$ ) and shorter hospital stays ( 10 days versus 11 days; 
$p=0.046)$. There was similar resection margin positivity, readmission, and 30-day mortality. Survival was similar between the matched groups at 3 years. A meta-analysis of 48 studies involving 14,311 patients revealed that compared to open patients, MIE patients experienced less in-hospital mortality, pulmonary complications, PE, and arrhythmias, with no differences in anastomotic leak. ${ }^{30}$ However, a systematic review and meta-analysis reporting on 6,058 patients treated between 1985 and 2015 resulted in higher hiatal hernia rates in MIE patients compared to open (4.5\% versus $1 \%) .{ }^{31}$ In a randomized trial of open versus MIE assessing quality of life at 1 year, MIE was shown to be superior for physical component, global health, and pain. ${ }^{32}$

\section{Esophagectomy volume and outcome}

Although the type of operation performed and approach (open versus MIE) can dictate patient outcomes, equally as influential is the overall volume of the surgeon. Surgical volume directly correlates to the surgeon's experience. The aforementioned prospective randomized trial by Biere et al, reported that patients who underwent esophagectomy (open or MIE) had an improvement in morbidity and mortality if they had operations performed by high-volume surgeons. Derogar et al in a nationwide Swedish population-based cohort study of 1,335 patients with esophageal cancer who underwent esophageal resection from 1987 to 2005 corroborated this finding. They demonstrated a $23 \%$ reduction in mortality when esophageal resections were performed by high-volume surgeons. ${ }^{33}$ These findings were independent of hospital volume.

\section{Robotic approaches to esophagectomy (RAIL)}

Utilization of robotics in surgery has the potential to increase accuracy in dissection through improved visualization and maneuverability while minimizing blood loss and postoperative recovery time. RAIL is a newer technique with some potential advantages over conventional minimally invasive approaches to esophagectomy. Traditional laparoscopic and thoracoscopic instruments are rigid, nonarticulating, with limited reticulation, and two-dimensional camera. Robotic arms have instrumentation that articulates and reticulates more so than a surgeon's capability. However, these movements more closely mimic open surgical techniques. The superior capabilities of the robotic arms improve maneuverability particularly in confined spaces. The additional fourarm allows the surgeon to switch between these instruments while also controlling the three-dimensional camera. This enhanced dexterity and visualization may lead to decreased manipulation of friable tissues while improving potential nodal harvest, thus allowing the surgeon to perform complex operations that historically could only be performed via open approaches. These benefits were acknowledged by surgeons which has been a dramatic increase in the usage of robotics for esophageal resection (Figure 1). Although the cost of using the surgical robot is significantly higher than other procedures, these costs may be offset by decreased $\mathrm{LOH}$, morbidity, and blood loss. ${ }^{34}$

\section{RAIL: technique Abdominal phase}

In the abdominal portion of the esophagectomy, five ports are often used (Figure 2). The patient is placed in a supine position on the operating table. The camera port is placed most often above the level of the umbilicus..$^{25,35-38}$ Two robotic

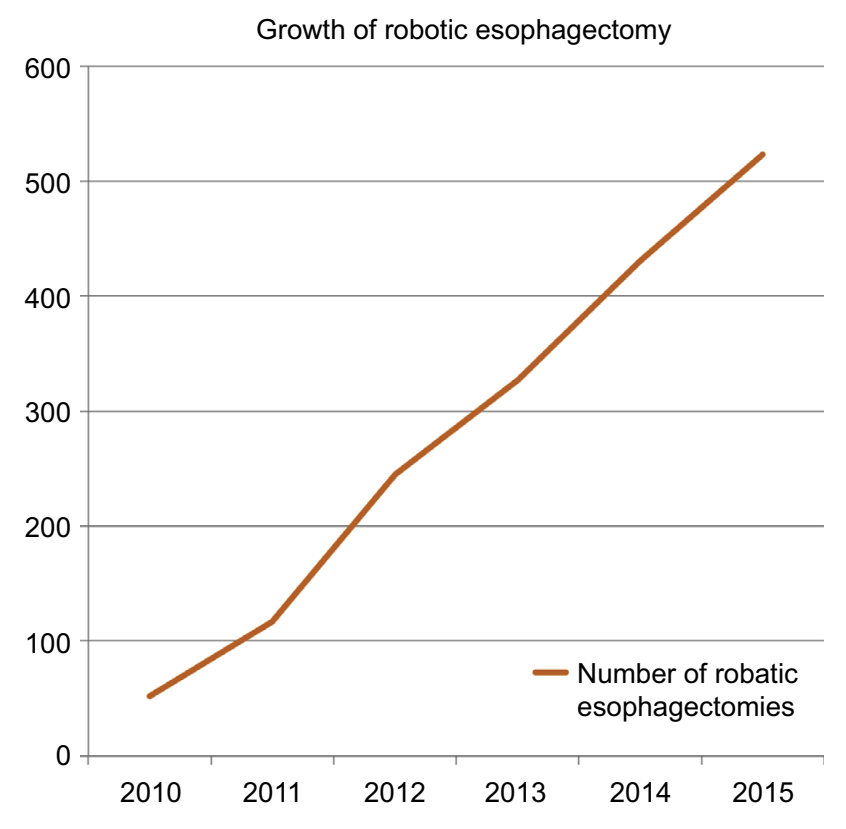

Figure I Increase in number of robotic esophagectomies.

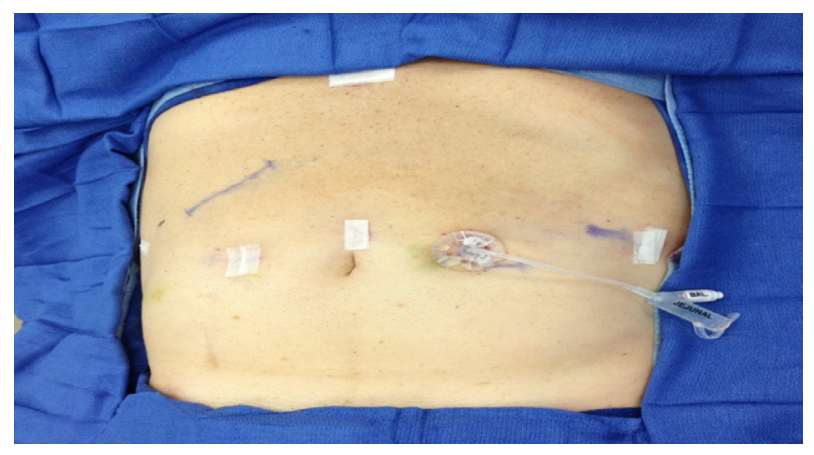

Figure 2 Abdominal phase port placement. 
surgical arms are then placed to the right (R.) lateral and right median positions ([one $8 \mathrm{~mm} \mathrm{R}$. lateral] and [one 10 $\mathrm{mm}$ for stapling R. paramedian]). A stab incision is made in the subxyphoid region for a Nathanson liver retractor, an 8 $\mathrm{mm}$ subcostal robotic port is placed in the left position, and an $8 \mathrm{~mm}$ assistant port is placed in the left paramedian position. The abdominal portion in all esophagectomies is used for gastric mobilization in preparation for the esophageal resection. The gastrocolic attachments are released while ensuring that the gastroepiploic vessels are preserved for future perfusion of the gastric conduit. The duodenum may be Kocherized depending on surgeon's preference; however, it is not required for transthoracic approaches. During the gastric mobilization phase, a celiac lymphadenectomy is also performed regularly. A pyloric emptying procedure is not routinely performed or indicated. In lieu of pylorplasty, the pylorus is injected in two locations with 300 units of Onabotulinum toxin A (Botox). A gastric conduit is then created with several fires of the robotic or laparoscopic stapler. A feeding jejunostomy tube is then placed and brought out through the existing $8 \mathrm{~mm}$ assistant port.

\section{Thoracic phase}

The patient is placed in a lateral decubitus position and the right thorax is entered through the sixth intercostal space, where an $8 \mathrm{~mm}$ port (10 $\mathrm{mm}$ port for SI system) is inserted for the robotic camera. A robotic port is then placed in the third intercostal space for robotic arm number 4 (XI system, arm 1 for SI system). A $4 \mathrm{~cm}$ incision is made at the ninth intercostal space, which serves as the access for the assistant (Figures 3, 4). An $8 \mathrm{~mm}$ robotic port is placed at the tenth posterior intercostal space for an additional robotic arm. The pleura over the azygos vein is incised and mobilized

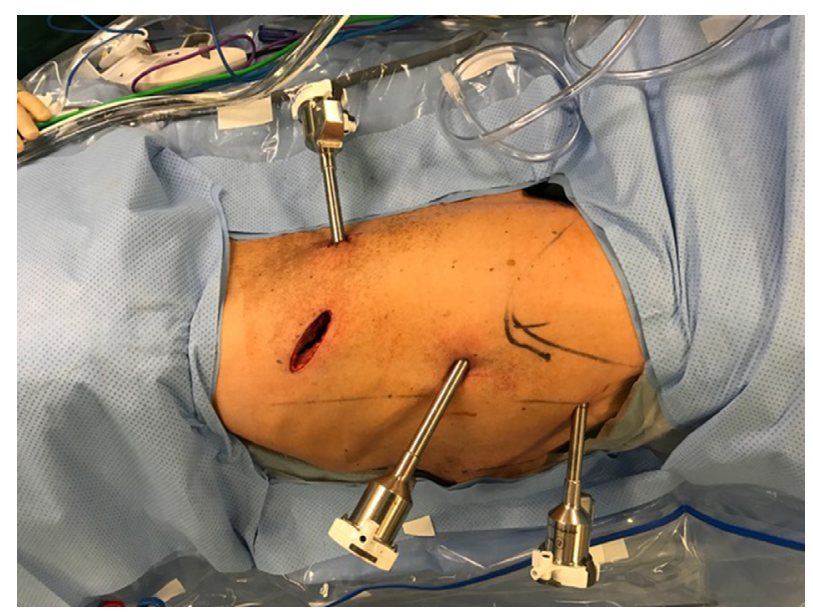

Figure 3 Chest phase port placement with extraction incision.

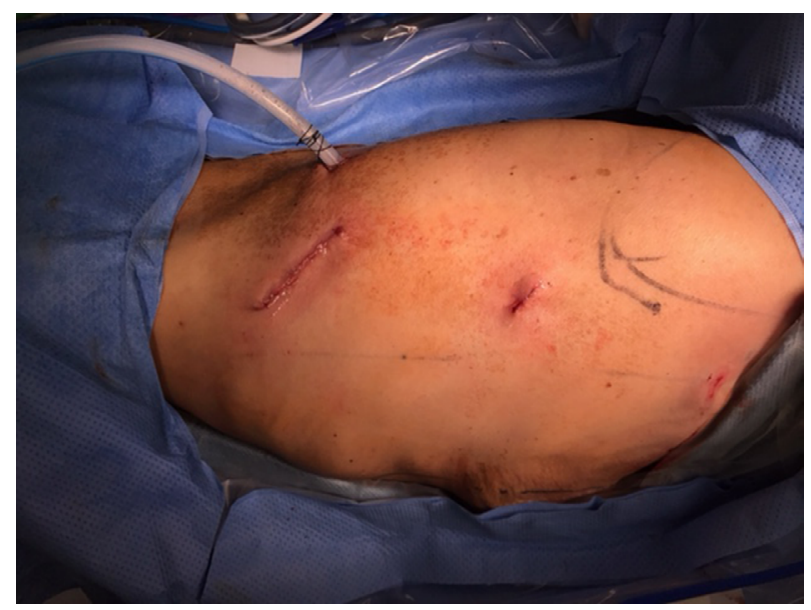

Figure 4 Chest phase port placement with chest tube.

completely with the hook cautery. The vein is transected with a vascular stapler. The esophagus is mobilized en bloc down to the gastroesophageal junction dissecting all visible lymph nodes in the periesophageal area, periaortic area, inferior pulmonary ligament, and subcarinal nodal basins. The specimen is then removed and checked for margin status. The esophagogastric anastomosis is created using a $25 \mathrm{~mm}$ anvil passed transorally (Orvil, Autosuture, Norwalk, CT, USA). After a nasogastric tube is brought down proximal to the newly created anastomosis, the chest is filled with saline and $40 \mathrm{~mL}$ of air is instilled into the proximal esophagus to check for anastomotic leaks. An omental patch is finally secured around the anastomosis.

\section{Outcomes with robotic approaches to esophagectomy}

When completed by an experienced surgeon, RAIL has comparable times to esophagectomies performed via thoracoscopic and laparoscopic approaches ${ }^{39}$ However, compared to the robotically assisted transhiatal esophagectomy (RATE), the operative time for RAIL was nearly double. ${ }^{35}$ The increase in operating time can be due to a number of factors, including the time necessary for moving the patient into the left lateral decubitus or prone position for the thoracic portion of the surgery, or the time needed to redock the robot for the thoracic phase. In an effort to decrease operating times, many surgeons used a hybrid procedure of laparoscopy for the abdominal phase and the robot for the thoracic phase. ${ }^{36}$ Although, as the surgeon increases his volume, the abdominal phase can be performed with comparable operative times. ${ }^{38}$

RAIL has demonstrated fewer complications (pulmonary, wound, cardiovascular, and overall) compared with open ILEs. ${ }^{40}$ In addition, LOH was significantly lower in 
the RAIL versus open. However, compared with RATE, RAIL results in increased pulmonary complications. ${ }^{41}$ This is likely due to the increased length of operation and longer time under single-lung ventilation. As the operative time for RAIL continues to decrease the pulmonary complications dropped, as shown by the continual decrease in the rates of postoperative pneumonia demonstrated by Hernandez et al. ${ }^{38}$ Conversely, RATE has increased rates of major complications compared to RAIL. These include an increased anastomotic leak rate, ${ }^{35,41}$ a higher incidence of recurrent laryngeal nerve injuries, wound complications, and aspiration. ${ }^{42,43}$ We have demonstrated similar results with our own retrospective analysis illustrating superior postoperative outcomes with RAIL compared to open and other MIE approaches. Anastomotic leaks, pneumonias, wound complications, and any complication were all found to be statistically lower in the cohort of patients who underwent RAIL (Table 1).

Although the R0 resection rates for RATE and RAIL may be equivalent, RAIL provides a better ability to perform an extended lymphadenectomy of the mediastinal lymph nodes which may have staging and survival implications. ${ }^{25,34,40,42}$ Lymph node retrieval in RATE is limited by the robotic arm's ability to fit through the diaphragmatic hiatus and visualization into the thoracic cavity from the abdomen. Therefore, the cephalad extent of lymph node dissection and nodal harvest in RATE is inferior compared to RAIL. In comparison of our own data with varying esophagectomy techniques, RAIL was superior to other techniques with median lymph node retrieval for open ILE, RAIL, MIE ILE, and MIE transhiatal being $10,20,14$, and $9, p=0.001$ (Table 2$).{ }^{44}$

\section{Learning curve for robotic-assisted esophagectomy}

The decrease in postoperative morbidity by MIE and robotics has not been reproduced in all surgeon's experience ${ }^{21,45,46}$ with many reporting significant complications early in the surgeon's learning curve. The learning curve for any operation is the number of times a particular procedure must be

Table I Comparison of outcomes with varying esophagectomy techniques

\begin{tabular}{|c|c|c|c|c|c|c|}
\hline $\begin{array}{l}\text { Surgical } \\
\text { complications }\end{array}$ & $\begin{array}{l}\text { Ivor Lewis, } \\
n=476(\%)\end{array}$ & $\begin{array}{l}\text { RAIL, } \\
n=\mid 44 \text { (\%) }\end{array}$ & $\begin{array}{l}\text { Transthoracic, } \\
\mathrm{n}=95 \text { (\%) }\end{array}$ & $\begin{array}{l}\text { Transhiatal, } \\
n=69(\%)\end{array}$ & $\begin{array}{l}\text { MIE transhiatal, } \\
n=63(\%)\end{array}$ & $p$-value \\
\hline Anastomotic leak & $23(4.8)$ & $4(2.8)$ & $4(4.2)$ & $9(13.0)$ & $4(6.3)$ & 0.03 \\
\hline Anastomotic stricture & $36(7.6)$ & II (7.6) & $3(3.2)$ & $19(27.5)$ & $16(25.4)$ & 0.001 \\
\hline Pneumonia & $52(10.9)$ & $10(6.9)$ & $13(13.7)$ & $12(17.4)$ & $24(38.1)$ & 0.001 \\
\hline Myocardial infarction & $6(1.3)$ & $\mathrm{I}(0.7)$ & $3(3.2)$ & I (I.4) & 0 & 0.4 \\
\hline Wound infection & $25(5.3)$ & I (0.7) & $6(6.3)$ & $4(5.8)$ & $10(15.9)$ & 0.001 \\
\hline $\begin{array}{l}\text { Cardiac arrhythmias } \\
\text { (includes A-fib) }\end{array}$ & $55(11.6)$ & $25(17.4)$ & 17 (I7.9) & $9(13.0)$ & $10(15.9)$ & 0.3 \\
\hline Any complication & 147 (30.9) & $34(23.6)$ & $29(30.5)$ & $44(63.8)$ & $39(61.9)$ & 0.001 \\
\hline Mortality & $7(1.5)$ & $2(1.4)$ & $2(2.1)$ & 0 & $2(3.2)$ & 0.6 \\
\hline
\end{tabular}

Abbreviations: MIE, minimally invasive esophageal surgery; RAIL, robotic-assisted Ivor Lewis esophagectomy.

Table 2 Operative demographics

\begin{tabular}{|c|c|c|c|c|c|c|}
\hline $\begin{array}{l}\text { Total cohort, } \\
\mathbf{N}=847\end{array}$ & $\begin{array}{l}\text { Ivor Lewis, } \\
n=476(\%)\end{array}$ & $\begin{array}{l}\text { RAIL, } \\
n=144(\%)\end{array}$ & $\begin{array}{l}\text { Transthoracic, } \\
n=95(\%)\end{array}$ & $\begin{array}{l}\text { Transhiatal, } \\
n=69(\%)\end{array}$ & $\begin{array}{l}\text { MIE transhiatal, } \\
n=63(\%)\end{array}$ & $p$-value \\
\hline \multicolumn{7}{|l|}{ Preoperative stage } \\
\hline $0-1$ & $55(14.8)$ & $34(25.0)$ & $13(15.5)$ & $14(27.5)$ & $10(18.9)$ & 0.03 \\
\hline II-IV & $317(85.2)$ & $102(75.0)$ & 7I (84.5) & 37 (72.5) & $43(8 I .1)$ & \\
\hline Neoadjuvant therapy & $274(57.6)$ & I I 2 (77.8) & $73(76.8)$ & $35(507)$ & $43(68.3)$ & 0.001 \\
\hline $\begin{array}{l}\text { Estimated blood loss } \\
(\mathrm{mL}, \text { mean } \pm S D)\end{array}$ & $288 \pm 354$ & $155 \pm 107$ & $189 \pm 188$ & $275 \pm 226$ & $242 \pm 380$ & 0.001 \\
\hline $\begin{array}{l}\text { Length of operation } \\
\text { (minute, mean } \pm S D \text { ) }\end{array}$ & $286 \pm 69$ & $409 \pm 104$ & $299 \pm 87$ & $273 \pm 89$ & $23 I \pm 65$ & 0.001 \\
\hline \multicolumn{7}{|l|}{ Resection } \\
\hline $\mathrm{RO}$ & 449 (94.7) & $144(100)$ & $86(93.5)$ & $62(89.9)$ & $60(96.8)$ & 0.04 \\
\hline RI & $18(3.8)$ & 0 & $6(6.5)$ & $5(7.2)$ & I (I.6) & \\
\hline $\mathrm{R} 2$ & $7(1.5)$ & 0 & 0 & $2(2.9)$ & I (I.6) & \\
\hline $\begin{array}{l}\text { Lymph node harvest } \\
\text { (mean } \pm S D)\end{array}$ & $10 \pm 6$ & $20 \pm 9$ & $14 \pm 7$ & $8 \pm 5$ & $9 \pm 6$ & 0.001 \\
\hline
\end{tabular}

Abbreviations: MIE, minimally invasive esophageal surgery; RAIL, robotic-assisted Ivor Lewis esophagectomy; SD, standard deviation. 
undertaken in order to complete it repeatedly with high accuracy and precision. ${ }^{47}$ There is an additional component to the learning curve which must be taken into consideration with application of innovative surgical procedures; this being postoperative morbidity and mortality.

Meredith et al defined the learning curve for RAIL in their series of 52 patients who underwent robotic-assisted esophageal resection for malignant esophageal disease via the transthoracic approach. They demonstrated a significant reduction in operative times following completion of 20 procedures (514 \pm 106 minutes versus $397 \pm 71.9$ minutes; $p<0.005)$. No conversions to open thoracotomy were required and there were no in-hospital mortalities with 30- and 90-day mortalities at $0.68 \%$ and $1.4 \%$, respectively. Complications were low, and not significantly different between any tenpatient cohort; however, there was a trend toward lower complications after the first 29 cases $(n=10$ [34\%] versus $n=4$ $[19 \%] p=0.07)$. They concluded that a surgeon must perform a minimum of 20 cases to surpass the technical component, and 29 cases for the postoperative morbidity component of the learning curve. ${ }^{38}$ This poses a significant issue for lowvolume surgeons as it would take 3 or more years to surpass their learning curve. Given the strong association between volume and outcomes, patients interested in minimally invasive and robotic esophageal resections should be referred to high-volume surgeons who are well above the learning curve for these technically challenging operations.

To decrease the learning curve for complex robotic procedures, some programs have instituted robotic training during surgical residency and fellowships with a combination of clinical and simulation tasks. These simulation tasks increase in complexity as the resident progresses. In addition, programs will track the total amount of time on the simulation modules to track progress. Once benchmarks are met, the residents and fellows are given increased responsibilities during the operative case as they progress. When the residents and fellows graduate, they should have obtained the necessary skills to expand their robotic practice to decrease their learning curve.

\section{Robotic-assisted approaches in special populations Neoadjuvant chemoradiotherapy}

NCR has been associated with significant perioperative morbidity and mortality ${ }^{48}$ However, there are scarce data on the use of neoadjuvant therapy in the MIE population. Shridhar et al reported on 89 RAIL patients, 69 of whom received NCR. ${ }^{49}$ The patients who underwent NCR had a higher body mass index (BMI) than those who went straight to esophagectomy (31 versus $27 ; p=0.001$ ). There were no conversions to open laparotomy or thoracotomy in either group. Overall complication rate was $19 \%$. There were no differences in the mean operative times, EBL, or complication rate. There were no deaths in either group and $\mathrm{LOH}$ as well as nodal harvest was similar. Coker et al reported on a small series of MIE THE patients treated with NCR. ${ }^{43}$ In their series, median operative time was 231 minutes and median EBL was $100 \mathrm{~mL}$. There were no conversions to open surgery. Complications included seven strictures, two anastomotic leaks, and two pericardial/ pleural effusions requiring drainage. One patient required pyloroplasty 3 months after esophagectomy. One patient died from pulmonary failure 21 days after surgery (30-day mortality rate of $4 \%$ ). The median length of stay was 9 days (range, 7-37 days). Seven of the 19 patients who underwent preoperative chemoradiation had a complete response on final pathology. The mean lymph node yield was 15 (range, 5-29), and surgical margins were negative for cancer in 21 cases.

\section{Elderly}

Abbott et al found that age did not correlate with complications. ${ }^{50}$ In that retrospective study, 134 patients who underwent MIE ILE, were stratified by age $(\leq 49,50-69$, and $\geq 70$ years). There was no statistically significant difference for operative time, $\mathrm{LOH}, \mathrm{AE}$, or mortality. The overall $\mathrm{AE}$ rate was $10 \%$ (cohort 1), $22 \%$ (cohort 2), and 35\% (cohort 3 ), $p=0.13$. There were five (4\%) leaks and two (1.5\%) deaths, but this was not significantly different between cohorts ( $p=0.40$ and $p=0.91$, respectively).

\section{Body mass index}

The impact of body weight on outcomes after robotic-assisted esophageal surgery for cancer has not been studied. Salem et al reported on the short-term operative outcomes in patients according to their BMI following RAIL at a highvolume tertiary-care referral cancer center and evaluated the safety of robotic surgery in patients with an elevated BMI. ${ }^{51}$ Patients were stratified by BMI index at admission for surgery according to World Health Organization criteria; normal range is defined as a BMI range of $18.5-24.9 \mathrm{~kg} / \mathrm{m}^{2}$. Overweight is defined as a BMI range of $25.0-29.9 \mathrm{~kg} / \mathrm{m}^{2}$ and obesity is defined as a BMI of $\geq 30 \mathrm{~kg} / \mathrm{m}^{2}$. One hundred twenty-nine patients were included with the majority of patients receiving neoadjuvant therapy. All patients had R0 resection. Median OR time was 407 minutes. Medians of OR time across the normal weight, overweight, and obese groups were 387, 395, and 445 minutes, respectively. Median 
EBL was $150 \mathrm{~cm}^{3}$. When stratified by BMI, medians of EBL across the normal weight, overweight, and obese groups were 100,150 , and $150 \mathrm{~cm}^{3}$, respectively. Obesity significantly correlated with longer OR time $(p=0.05)$, but without significant increased EBL $(p=0.348)$. Among the three BMI groups, there was no difference in postoperative complications including thrombotic events (PE and DVT) $(p=0.266)$, pneumonia $(p=0.189)$, anastomotic leak $(p=0.090)$, wound infection ( $p=0.390)$, any cardiac events ( $p=0.793)$, or 30-day mortality $(p=0.414)$.

\section{Conclusion}

MIE results in fewer pulmonary complications, shortened hospital stays, and improved quality of life without compromising oncologic outcomes, such as margin status, nodal harvests, and most importantly, survival compared to open approaches. The RAIL demonstrates similar outcomes compared to other MIE techniques. RAIL can also safely be performed with additional efficacy demonstrated in elderly patients, obese patients, and in patients who undergo neoadjuvant therapy. Although there is a substantial learning curve associated with RAIL, as the number of cases performed increases, the length of operation and postoperative morbidity is decreased. Given the steep learning curve, and strong association with surgeon volume and operative outcomes, patients interested in this approach should be referred to high-volume surgeons who have surpassed their learning curve. Future comparisons between minimally invasive and robotic techniques are needed to determine the best approach for esophageal resection.

\section{Disclosure}

The senior author, Kenneth Meredith, serves as a case observation site for minimally invasive esophagectomy for Ethicon and Intuitive. The authors report no other conflicts of interest in this work.

\section{References}

1. Siegel RL, Miller KD, Jemal A. Cancer statistics, 2016. CA Cancer J Clin. 2016;66(1):7-30.

2. Sjoquist KM, Burmeister BH, Smithers BM, et al. Survival after neoadjuvant chemotherapy or chemoradiotherapy for resectable oesophageal carcinoma: an updated meta-analysis. Lancet Oncol. 2011;12(7):681-692.

3. van Hagen P, Hulshof MC, van Lanschot JJ, et al. Preoperative chemoradiotherapy for esophageal or junctional cancer. $N$ Engl $J$ Med. 2012;366(22):2074-2084.

4. Coupland VH, Lagergren J, Luchtenborg M, et al. Hospital volume, proportion resected and mortality from oesophageal and gastric cancer: a population-based study in England, 2004-2008. Gut. 2013;62(7):961-966.

5. Hanna GB, Boshier PR, Knaggs A, Goldin R, Sasako M. Improving outcomes after gastroesophageal cancer resection: can Japanese results be reproduced in Western centers? Arch Surg. 2012;147(8):738-745.
6. Atkins B, Shah A, Hutcheson K, et al. Reducing hospital morbidity and mortality following esophagectomy. Ann Thorac Surg. 2004;78(4):1170-1176.

7. Bedenne L, Michel P, Bouche O, et al. Chemoradiation followed by surgery compared with chemoradiation alone in squamous cancer of the esophagus: FFCD 9102. J Clin Oncol. 2007;25(10):1160-1168.

8. Chang AC, Ji H, Birkmeyer NJ, Orringer MB, Birkmeyer JD. Outcomes after transhiatal and transthoracic esophagectomy for cancer. Ann Thorac Surg. 2008;85(2):424-429.

9. Gebski V, Burmeister B, Smithers BM, et al. Survival benefits from neoadjuvant chemoradiotherapy or chemotherapy in oesophageal carcinoma: a meta-analysis. Lancet Oncol. 2007;8(3):226-234.

10. Jin J, Liao Z, Zhang Z, et al. Induction chemotherapy improved outcomes of patients with resectable esophageal cancer who received chemoradiotherapy followed by surgery. Int J Radiat Oncol Biol, Phys 2004;60(2):427-436.

11. Karl R, Schreiber R, Boulware D, Baker S, Coppola D. Factors affecting morbidity, mortality, and survival in patients undergoing Ivor Lewis esophagogastrectomy. Ann Surg. 2000;231(5):635-643.

12. Kelsen DP, Winter KA, Gunderson LL, et al. Long-term results of RTOG trial 8911 (USA Intergroup 113): a random assignment trial comparison of chemotherapy followed by surgery compared with surgery alone for esophageal cancer. J Clin Oncol. 2007;25(24):3719-3725.

13. Pennathur A, Luketich JD, Landreneau RJ, et al. Long-term results of a phase II trial of neoadjuvant chemotherapy followed by esophagectomy for locally advanced esophageal neoplasm. Ann Thorac Surg. 2008;85(6):1930-1936; discussion 6-7.

14. de Boer AG, van Lanschot JJ, van Sandick JW, et al. Quality of life after transhiatal compared with extended transthoracic resection for adenocarcinoma of the esophagus. J Clin Oncol. 2004;22(20):4202-4208.

15. Earlam R, Cunha-Melo JR. Oesophageal squamous cell carcinoma: I A critical review of surgery. Br J Surg. 1980;67(6):381-390.

16. Hulscher JB, van Sandick JW, de Boer AG, et al. Extended transthoracic resection compared with limited transhiatal resection for adenocarcinoma of the esophagus. N Engl J Med. 2002;347(21):1662-1669.

17. Orringer MB, Marshall B, Chang AC, et al. Two thousand transhiatal esophagectomies: changing trends, lessons learned. Ann Surg. 2007;246(3):363-372; discussion 72-74.

18. Rizzetto C, DeMeester SR, Hagen JA, Peyre CG, Lipham JC, DeMeester TR. En bloc esophagectomy reduces local recurrence and improves survival compared with transhiatal resection after neoadjuvant therapy for esophageal adenocarcinoma. J Thorac Cardiovasc Surg. 2008; 135(6):1228-1236.

19. Wu PC, Posner MC, Wu PC, Posner MC. The role of surgery in the management of oesophageal cancer. Lancet Oncol. 2003;4(8):481-488.

20. Bizekis C, Kent MS, Luketich JD, et al. Initial experience with minimally invasive Ivor Lewis esophagectomy. Ann Thorac Surg. 2006;82(2):402406; discussion 6-7.

21. Law SY, Fok M, Wei WI, et al. Thoracoscopic esophageal mobilization for pharyngolaryngoesophagectomy. Ann Thorac Surg. 2000;70(2):418-422.

22. Luketich JD, Alvelo-Rivera M, Buenaventura PO, et al. Minimally invasive esophagectomy: outcomes in 222 patients. Ann Surg. 2003;238(4):486-494; discussion 494-495.

23. Merritt R. Initial experience of total thoracoscopic and laparoscopic Ivor Lewis esophagectomy. J Laparoendosc Adv Surg Tech A. 2012; 22(3):214-219.

24. Luketich JD, Pennathur A, Awais O, et al. Outcomes after minimally invasive esophagectomy: review of over 1000 patients. Ann Surg. 2012;256(1):95-103.

25. De la Fuente SG, Weber J, Hoffe SE, Shridhar R, Karl R, Meredith, $\mathrm{KL}$. Initial experience from a large referral center with robotic-assisted Ivor Lewis esophagogastrectomy for oncologic purposes. Srug Endosc. 2013;27(9):3339-3347.

26. Biere S, Van Berge Henegouwen M, Maas K, et al. Minimally invasive versus open oesophagectomy for patients with oesophageal cancer: a multicentre, open-label, randomised controlled trial. Lancet. 2012;379(9829): $1887-1892$. 
27. Guo M XB, Sun X, Hu M, Yang Q, Lei Y. A comparative study of the theraspeutic effect in two protocols: video-assisted thoracic surgery combined with laparoscopic versus rightr open transthoracic esophagectomy for esophageal cancer management. Chin Ger Clin Oncol. 2013:1268-1271.

28. Sihag S, Kosinski AS, Gaissert HA, Wright CD, Schipper PH. Minimally invasive versus open esophagectomy for esophageal cancer: a comparison of early surgical outcomes from the society of thoracic surgeons National Database. Ann Thorac Surg. 2016;101(4):1281-1288; discussion 1288-1289.

29. Yerokun BA, Sun Z, Jeffrey Yang CF, et al. Minimally invasive versus open esophagectomy for esophageal cancer: a population-based analysis. Ann Thorac Surg. 2016;102(2):416-423.

30. Zhou C, Zhang L, Wang H, et al. Superiority of minimally invasive oesophagectomy in reducing in-hospital mortality of patients with resectable oesophageal cancer: a meta-analysis. PLoS One. 2015;10(7):e0132889.

31. Oor JE, Wiezer MJ, Hazebroek EJ. Hiatal hernia after open versus minimally invasive esophagectomy: a systematic review and meta-analysis. Ann Surg Oncol. 2016;23(8):2690-2698.

32. Maas KW, Cuesta MA, van Berge Henegouwen MI, et al. Quality of life and late complications after minimally invasive compared to open esophagectomy: results of a randomized trial. World J Surg. 2015;39(8):1986-1993.

33. Derogar MS-A O, Johar A, Lagergren P, Langergren J. Hospital and surgeon volume in relation to survival after esophageal cancer surgery in a population-based study. JCO. 2013;21(5):551-557.

34. Puntambekar S, Kenawadekar R, Kumar S, et al. Robotic transthoracic esophagectomy. BMC Surg. 2015;15:47.

35. Dunn DH, Johnson JA, Morphew JA, et al. Robot-assisted transhiatal esophagectomy: a 3-year single-center experience. Dis Esophagus. 2013;26(2):159-166.

36. Hodari A, Park KU, Lace B, Tsiouris A, Hammoud Z. Robot-assisted minimally invasive Ivor Lewis esophagectomy with real-time perfusion assessment. Ann Thorac Surg. 2015;100(3):947-952.

37. Sarkaria IS, Rizk NP, Finley DJ, et al. Combined thoracoscopic and laparoscopic robotic-assisted minimally invasive esophagectomy using a four-arm platform: experience, technique and cautions during early procedure development. Eur J Cardiothorac Surg. 2013;43(5):e107-115.

38. Hernandez J, Dimou F, Weber J, et al. Defining the learning curve for robotic-assisted esophagogastrectomy. J Gastrointest Surg. 2013; 17(8):1346-1351.
39. Meredith K, Andacoglu O, Hoffe S, Almhanna K, Shridhar R. 147 Robotic Assisted Ivor Lewis Esophagectomies: Safety and Feasibility. In press 2017.

40. Boone J, Schipper ME, Moojen WA, Borel Rinkes IH, Cromheecke GJ, van Hillegersberg R. Robot-assisted thoracoscopic oesophagectomy for cancer. Br J Surg. 2009;96(8):878-886.

41. Mori K, Yamagata Y, Aikou S, et al. Short-term outcomes of robotic radical esophagectomy for esophageal cancer by a nontransthoracic approach compared with conventional transthoracic surgery. Dis Esophagus. 2016;29(5):429-434.

42. Cerfolio RJ, Bryant AS, Hawn MT. Technical aspects and early results of robotic esophagectomy with chest anastomosis. J Thorac Cardiovasc Surg. 2013;145(1):90-96.

43. Coker AM, Barajas-Gamboa JS, Cheverie J, et al. Outcomes of robotic-assisted transhiatal esophagectomy for esophageal cancer after neoadjuvant chemoradiation. J Laparoendosc Adv Surg Tech A. 2014;24(2):89-94.

44. Yamamoto M, Weber J, Karl R, Meredith K. Minimally invasive surgery for esophageal cancer: Review of the literature and the institutional experience. Cancer Control. 2013;20(2):130-137.

45. Martin DJ, Bessell JR, Chew A, Watson DI. Thoracoscopic and laparoscopic esophagectomy: initial experience and outcomes. Surg Endosc. 2005;19(12):1597-1601.

46. Nguyen N, Hinojosa M, Smith B, Chang K, Gray J, Hoyt D. Minimally invasive esophagectomy: lessons learned from 104 operations. Ann Surg. 2008;248(6):1081-1091.

47. Teplitz CJ. The Learning Curve Deskbook: A Reference Guide to Theory, Calculations, and Applications. New York, NY: Quorum Books; 1991.

48. Shridhar R, Almhanna K, Meredith KL, et al. Radiation therapy and esophageal cancer. Cancer Control. 2013;20(2):97-110.

49. Shridhar R, Abbott AM, Doepker M, Hoffe SE, Almhanna K, Meredith KL. Perioperative outcomes associated with robotic Ivor Lewis esophagectomy in patient's undergoing neoadjuvant chemoradiotherapy. J Gastrointest Oncol. 2016;7(2):206-212.

50. Abbott A, Shridhar R, Hoffe S, et al. Robotic assisted Ivor Lewis esophagectomy in the elderly patient. J Gastrointest Oncol. 2015;6(1): 31-38.

51. Salem AI, Thau MR, Strom TJ, et al. Effect of body mass index on operative outcome after robotic-assisted Ivor-Lewis esophagectomy: retrospective analysis of 129 cases at a single high-volume tertiary care center. Dis Esophagus. 2017;30(1):1-7.
Robotic Surgery: Research and Reviews

\section{Publish your work in this journal}

Robotic Surgery: Research and Reviews is an international, peer reviewed, open access, online journal publishing original research, commentaries, reports, and reviews on the theory, use and application of robotics in surgical interventions. Articles on the use of supervisory-controlled robotic systems, telesurgical devices, and shared-control systems are

\section{Dovepress}

invited. The manuscript management system is completely online and includes a very quick and fair peer review system, which is all easy to use. Visit http://www.dovepress.com/testimonials.php to read real quotes from published authors. 